\title{
ON THE SPINAL ANIMAL
}

\author{
BEING THE \\ MARSHALL HALL PRIZE ADDRESS
}

BY

CHARLES S. SHERRINGTON,

M.A., M.D., F.R.S.

Read May 23rd, 1899.

Mr. Presiden'i and Gen'llemen,

When your Society was kind enough to recognise some work of mine by the coveted Marshall Hall Prize, it extended to me at the same time your hospitality for a short address. In answer to that invitation I now venture to lay before you a few remarks regarding the physiology of the spinal cord. That the prize bequest to the Society is associated with the name of Marshall Hall sufficiently, I think, justifies my choice of such a theme.

Marshall Hall, like not a few investigators of enthusiasm, seems to have been at little pains to know what of his subject had been ascertained by previous workers. $\mathrm{He}$ concluded from his own observations that the spinal cord and the whole nervous system could be well regarded from the physiological standpoint as a linked series of reflex arcs. The idea was not a new one, but in his hands it obtained new illustrative facts. The doctrine of the cord as a spinal chain of functional segments the units of which are reflex arcs, gained much furtherance from the advocacy of Marshall Hall.

The segmental arrangement of the spinal nerves in their gross anatomy does not, of course, necessarily carry 
with it any proof of the functional segmentation of the cord. That proof can be furnished only by analysis of the functional plan. A point of first importance for this question is the capacity of the fractionated spinal cord. Herbert Mayo ${ }^{1}$ by his experiment showing the pupil reflex to be elicitable when but a single cranial segment remains, and Legallois ${ }^{2}$ by his localisation of the respiratory centre in the bulb, had at the outset of the century laid the foundation of the segmental theory of the functions of the cord. Marshall Hall ${ }^{3}$ and Grainger ${ }^{4}$ further contributed experiments demonstrating the functional powers of spinal fractions. The latter drew significant observations from the reflex movements of invertebrata. The study of the functions of the nervechain of invertebrata became later neglected, most unwisely. Quite recently such work has vigorously been resumed. An example of its fruitfulness for the present problem is furnished by the observations of $\mathrm{Hyde}^{5}$ on Limulus made in the Laboratory of Professor Loeb, of Chicago.

When in Limulus all that is analogous to the brain has been ablated, and indeed only the abdominal region of the spinal cord remains, the rhythmic respiratory movements of the abdominal segments still proceed regularly and co-ordinately. Even when a fraction of the nervecord, separated by transections in front and behind, is left corresponding with a single abdominal segment, the musculature of that segment continues its rhythmic action. Its rhythm is then no longer timed to that of the adjacent segments ; its co-ordination with the rest is destroyed but its activity is maintained. Its activity ceases only if the segmental fraction of the spinal cord is itself destroyed. This instance is paralleled by the sexual " clasp " reflex of the brachial segments of the male frog, maintained when

\footnotetext{
1 'Physiol. Commentaries,' London, 1823.

21830.

3 'Memoirs on the Nervous System,' London, 1838.

4 'Functions of the Spinal Cord,' London, 1837.

5 'Journ. of Morphology,' 1894, vol. ix.
} 
all the rest of the central nervous system is destroyed. ${ }^{1}$ Similarly in the cat and monkey, the reflex wagging of the tail persists when behind the spinal transection only the sacral region of the cord is left intact.

To judge how far the reactions of the spinal organ can be really considered as segmentally arranged, it is important to have a conception as clear as possible of the spatial relations of the spinal nerve-cells. The delineation of the spinal segment usually given presents its true extension very imperfectly.

The edifice of the whole nervous system is based, as upon two pillars, upon two nerve-cells, the afferent rootcell, and the efferent root-cell. These form a fundamental spinal arch upon which all other neural arcs are superposed and functionally rest, immediately or mediatelyeven those of the hemispheral cortex. The afferent rootcells of the spinal axis may be arranged in three great groups: (1) cutaneous, from the sense organs of the skin; (2) "muscular," from the sense organs of the musculoarticular apparatus ; (3) " sympathetic," from the viscera. Each spinal afferent root consists typically of three constituent roots-a cutaneous, a muscular, and a visceral. The efferent root-cells are conveniently grouped in two sets, one supplying skeletal muscles (1), the other entering the sympathetic chrin (2) to innervate the musculature of the blood-vessels, of the skin, and of the viscera, including some secretory apparatus in the two latter.

To deal with the afferent root-cells first. The cutaneous afferent root-cells have their perikarya or cell bodies in the spinal ganglion. Probably in each one of the spinal ganglia the majority of the cells belong to nerve-fibres afferent from skin. The peripheral distribution of the collection of cutaneous nerve-ceils of each spinal ganglion occupies a semi-zonal field of body surface. ${ }^{2}$ The zone is relatively wide and invests a little more than the entire width of one lateral half of the body, trespassing slightly across the

1 Goltz, 'Centralb. f. med. Wissensch.,' 1870.

2 Sherrington, 'Phil. 'Trans.,' 1892, London. 
middle line both ventrally and dorsally. In the regions of the trunk and neck and perinæum this zonal arrangement is quite obvious, but in the regions of the limbs it is less so, and at first sight appear's departed from. The skin fields of the last three cervical and the first two thoracic and of the last two lumbar and the first two sacral ganglia are entirely confined to the limb and do not meet the middle line of the body either ventrally or dorsally. But when the skin fields of the ganglia of the limb ${ }^{1}$ region had been carefully ascertained the results collated showed clearly that both in the brachial and in the pelvic limbs the zonal form of the fields still obtains, each semi-zone being wrapped half round the limb instead of half around the body. Hence exist what I have termed the ventral and dorsal axial lines of the limbs; these, forming, as it were, lines of watershed between the systems of semizones (Pl. XIII), meet at their one end the mid-ventral and mid-dorsal lines of the body, and may be looked upon aslateral extensions thereof. 'They are not hypothetical, for they are exhibited in the striping of animals. The dorsal axial line of the hind limb is particularly well seen in the tiger, the stripes in that limb starting from it ; the dorsal axial line of the fore limb is in the same way well seen in the zebra. The dorsal axial lines of the fore limbs, diverging from the dorsal median line of the body, are in the ass usually marked by heavier pigmentation of the coat, thus making the "sign of the Cross" well known on the ass's shoulders. These axial lines of the limbs are of much clinical importance, for they are the boundaries observed by the upper limits of the anæsthesia accompanying injuries to the spinal cord or spinal roots in the regions of the lower and upper limbs respectively.

The skin fields belonging to the spinal ganglia are wide, and that for each ganglion largely overlaps its neighbours. In the inonkey I have not been able to satisfy myself that there is any patch of skin in the neck, trunk, or limbs that is not in receipt of sensory supply

1 Sherrington, 'Phil. Trans. Roy. Soc.,' London, 1892. 
from each of two adjacent spinal ganglia. In certain regions (e.g. the hand, the foot, the pinna of the ear) the skin receives sensory fibres from each of three adjacent ganglia. ${ }^{1}$ This explains how it is that the limb plexuses exist. The peripheral nerves of the limbs have to obtain components from more than one spinal nerve root. The innervation of the limb musculature is similarly plurisegmental. If, therefore, the spinal ganglion be considered a segmental collection of nerve-cells, those nerve-cells at their peripheral endings impinge on the body-surface over a zonal area which overlaps slightly with the contra-lateral zonal areas across the ventral and dorsal lines, and overlaps greatly with the collateral zonal areas next in front and next behind (headward and tailward) of itself. This zonal skin area may be considered a " segmental field" of skin.

As to which of the cell-bodies in the spinal ganglion belong to the skin-fibres, the probability is that the size of the nerve-fibres is a guide to the size of the cells, and that the "skin" cells are neither the largest nor the majority of the very smallest; they are probably the majority of the medium-sized cells.

The visceral constituent of the spinal ganglion is probably in all the ganglia numerically the weakest. It can be considered as practically if not absolutely wantiug in the cervical ganglia and in the ganglia of the lower lu inbar nerves. In order to estimate what number of the cells in a thoracic ganglion belong to its afferent path from the viscera, all that is necessary is to divide the spinal roots afferent and efferent proximal to the ganglion, and subsequently, when time has been allowed for degeneration, to count the number of myelinate fibres remaining sound in the white ramus communicans. In this way I found the sensory ganglion of the tenth thoracic nerve of the cat contain some 130 visceral nerve-cells; and since the fibres are small the cells are probably small also.

It is curiously difficult to initiate reflex reactions by 1 Sherrington, 'Phil. Trans. Roy. Soc.,' London, 1892. 
sensory stimuli applied to the viscera themselves. In his great essay on "The Parts that feel and the Parts that do not feel," " Albert von Haller in the last century brought forward abundant evidence of the extraordinary violence of insult that may be inflicted on the viscera even in absence of all anæsthesia-his observations were a hundred years prior to the advent of anæsthetics-and yet fail to evoke of sensation any sign whatsoever. Certain visceral conditions are, however, well known to be characterised by extremity of pain-instance the pain of renal or of biliary colic. In order to examine the afferent channels from viscera, I have had recourse to vascular reflexes obtainable in anæsthetised animals, and find they can be strikingly well provoked by the injection of a little fluid into such passages as the ureter and bile-duct. The mechanical distension transiently produced by injecting a few cubic centimetres of saline solution into the blle-duct immediately and regularly evokes a marked rise of arterial pressure. Plates XIV and XV are instances of the reactions which occur, typical bulbo-spinal reflex actions implicating the vaso-motor system ; vaso-motor spasm of considerable intensity and often presenting a double maximum succeeds each irritation.

These reactions seem to offer a means of experimentally determining the exact paths along which nervous impulses travel from these viscera to the spinal axis. I hope shortly to finish the work I have commenced in that. direction; the results obtained confirm those published by Dr. Bradford on the kidney, ${ }^{2}$ and by Dr. Head ${ }^{3}$ on the ureter and other viscera; from the liver the afferent path as regards nerve-roots seems especially wide. Regarding overlap of distribution in the viscera neurons lying in adjacent spinal ganglia, little or nothing is known. Of the three great sets of channels, vagus, thoracic afferent roots, and sacral afferent roots, it is probable that at their

\footnotetext{
1 'Opera Minora,' vol. i, Lausanne, 1772.

2 Foster's ' Journal of Physiol.,' vol. xi, 1891.

3 'Brain,' 1893.
} 
boundaries there is some overlapping in their peripheral distribution.

It has by a number of authorities ${ }^{1}$ been denied that the skeletal muscles possess afferent nerves, but analysis of the nerve-trunks, entering and supplying the muscles, into their component fibres derived from the ventral and dorsal spinal nerve-roots respectively, demonstrates that the skeletal muscles receive quite a large number of nerve-fibres that are sensory. These nerve-fibres vary much in size, and some of them are the largest afferent nerve-fibres in the body. Many of them are, however, very minute, and these last seem to end in relation with the blood-vessels of the muscles. The seuse-organs in the skeletal muscles are the "muscle-spindles," the tendon organs of Golgi, the end-bulb-like bodies in perineurium, the end-organs placed at junction of musclefibre and tendon especially exemplified in the eye muscles, and a few Pacinian corpuscles. In the nerves to some muscles the afferent fibres are as numerous as the efferent. It is probable that the very largest cells in the spinal ganglia belong to some of the nerve-fibres of the muscle-spindles. Probably in every spinal ganglion a number of the nerve-cells belong to the sense organs of muscle.

The topographical distribution of the afferent neurons of the skeletal muscles at the periphery will be best dealt with after dealing with that of the motor root-cells themselves, and these will now be taken.

Regarding the efferent root-cells of the spinal cord, these, like the afferent, are divisible into three groupsthose related to the skeletal musculature, to the skin, and to the viscera. The position of the nerve-cell bodies or perikarya of these efferent neurons, unlike that of the afferent, is intra-spinal. There is good evidence that they lie embedded in the cord at the same segmental level as the point of emergence from the cord of the nerve-fibres

\footnotetext{
1 v. Haller, Schiff, Kühne, \&c.
} 
they originute. If into the cord a clean incision be made transversely to its length, there ensues degeneration of the motor root fibres immediately at the site of the trauma and not in front of or behind that level; the root-fibres therefore do not take their origin any distance in front of or behind their point of exit or they would suffer degeneration. This is well seen in regions where each motor root consists of a series of rootlets. It proves each rootlet to be a collection of fibres which represents the nerve-cells lying in its own particular level of the grey matter, in fact, so to say, which drains only one particular cross-level of the cord. This fact can be combined with the further observation that each coustituent nutural rootlet of the motor root contains fibres which, broadly speaking, are distributed to all the structures which the entire root innervates. $^{2}$ Each rootlet of the root can thus be described as representing in miniature the entire root. It follows that the position of the nerve-cells sending motor fibres to any one skeletal muscle is a scattered one, extending throughout the whole length of the spinal segments innervating that muscle; in the limb regions many muscles receive their motor fibres from as many as three consecutive spinal roots, and the bodies of the nerve-cells innervating those must therefore, inside the cord, extend through the length of three whole segments of the cord as a continuous columnar group, and in each transverse level of the cord these cells must lie commingled with nerve-cells innervating many other muscles. Hence no traumatic injury of the spinal cord can ever paralyse a single muscle alone and apart from others. Even the sererance of any one whole motor nerve-root cannot paralyse a single limb muscle; the effect of such an injury is to partially impair a large number of the muscles. ${ }^{3}$

1 Sherrington, ' Journ. of Physiol.,' vol. xiv, 1892. A. S. F. Grünbaum, ibid., vol. xvi, 1894 .

2 Sherrington, 'Journ. of Physiol.,' vol. xiii, 1892.

3 Sherrington, ibid. 
Analysis of the spinal nerve-supply of the muscles of either limb demonstrates that the muscular tissue of the limb is arranged in a number of rays, ${ }^{1}$ there being one ray for each one metamer contributing to the limb. Of these rays the tailmost in the fore-and-aft series are the longest; they extend to the extreme free apex of the limb, whereas the foremost, the most rostral, pass only as far as the thigh, the next hindward as far as the knee, the next hindward as far as the ankle. In the fore limb of Macacus rhesus, the common rhesus monkey, the four hindmost, most aboral rays all contribute to the musculature of the hand. When we inquire how these units of the segmental architecture of the limbs, these muscular rays, are related to the physiological or functional units of the limb musculature, it is at once obvious that the extent and boundaries of the two do not coincide. The definitely-bounded, individual and circumscribed masses of muscular tissue which are known as "the muscles" of the limb are functional elements of its structure as a physiological machine. But each of these functional elements is compounded and pieced together out of several rays or myotoms. Moreover, the boundaries between the myotoms do not correspond with the intervals, between muscles nor even with those between muscle-groups. Degeneration experiments which enable one to follow the distribution of the individual nervefibres of a root show that in some muscles the number of motor nerve-fibres given by a spinal root to a muscle is too small to evoke from the muscle any contraction obvious to inspection, for cases occur where a limbmuscle receives three, four, or five motor nerve-fibres from a particular nerve-root. This I regard as strong testimony to the morphological character of the overlap. ${ }^{2}$

Another feature of the distribution of the motor fibres of the spinal root to a muscle is the remarkable fre-

1 Sherrington, 'Journ. of Physiol.,' vol. xiii, 1892.

2 Sherrington, Presidential Address to the Biological Society of Liverpool, 1898. 
quency with which it is subject to slight individual variation. In examining a series of individuals (cats, monkeys) it is almost rare to meet two consecutive members of the series in which the root distribution is not by the degeneration or experimental method demonstrably somewhat different. Thus as instance I found in some individuals supinator brevis innervated from the sixth and fifth cervical nerves, in others, from the sixth and seventh. In the former case the innervation of the muscle may be termed "prefixed" type, in the latter "post-fixed." In my observations I considered it sufficient to group the individuals into two classes, a post-fixed and a prefixed. The absolute segmental level of a muscle is variable over the range of nearly a whole segment's length; the relative segmental position is, however, preserved inviolably constant.

As regards the afferent nerve-fibres of the skeletal muscles, after their existence had been proved by the degeneration method, it was possible by the same method to examine their relation to the spinal segments. The result of such examination shows that not only are the skeletal muscles in many instances, pre-eminently in the limbs, plurisegmental as regards their motor innervation, but that they are so also in regard to afferent innervation. I was able to show ${ }^{2}$ that the afferent nerve-fibres distributed to a given muscle arise in the root ganglia of exactly those spinal segments whence emerge the motorfibres for the same muscle. In other words, the sensory nerve-cells directly connected with a given skeletal ınuscle are in any one individual always of the same segmental level as are the motor nerve-cells connected with the same given muscle. In so far, therefore, the simplest reflex arc connected with a muscle may be expeoted to lie exactly in those segments, whence issue the motor fibres of the muscle; and is a segmental arc. In the "knee-jerk" we have evidence of a reflex arc traceable mainly from

1 Sherrington, 'Journ. of Physiol.,' vol. xiii, 1892.

2 'Phil. Trans. Roy. Soc.,' London, 1896. 
and into vastus medialis and adjacent part of crureus, ${ }^{1}$ and this affords, as it were, a test case for the above conclusions. It confirms them perfectly. It exemplifies them by its narrow local extent, and by the segmentally horizontal correlation of the motor and sensory components.

What was said above to show that the intra-spinal site of the efferent root-cells is at the segmental level of the point of emergence of the motor cell-fibres itself applies to the motor nerve-cells of the sympathetic system, as well as to those of the skeletal muscles. The sympathetic efferent cells are not, however, present in all spinal segments, but are, as above noted, absent from the cervical and lower lumbar. They are distributed peripherally to the motor cells of the pre-vertebral ganglia of the sympathetic chain, and constitute the system of fibres which Langley ${ }^{2}$ calls pre-ganglionic. Their distribution to the ganglia is an overlapping one, so that each pre-vertebral ganglion contains endings from a short series of sympathetic efferent spinal roots. Hence it is that so small a muscle as the iris receives efferent fibres from three spinal roots ; in the monkey the first, second, and third thoracic. ${ }^{3}$

It has by many been supposed that even in the cord of the higher vertebrata the collection of the perikarya of the efferent root-cells corresponding as they do with that of the afferent root-cells which form the spinal ganglia must be massed into a group for each' spinal segment, separated by a distinct interval from that of the next segment. ${ }^{4}$ As a fact, not only is evidence of such an arrangement as this wanting, but the evidence as regards the mammalian cord refutes the supposition. ${ }^{5}$ So complete a fusion of the individual segments has in the course of ages gone on that, as regards the position of the efferent cells inside the cord, although no demonstrable degree of

1 Sherrington, 'Journ. of Physiol.,' xiii, 1892.

2 'Journ. of Physiol.,' xv, 1894.

3 Sherrington, 'Journ. of Physiol.,' xiii, 1892.

4 Schwalbe.

5 Kaiser, v. Argutinski. 
segmental interlap exists, yet also there is now existent no dernonstrable segmental interval.

Just as the peripheral distribution of the afferent fibres of the spinal ganglia is an overlapping one, so also is their central intra-spinal ramification. The central or stemprocess of each afferent root-cell, after entering the cord, bifurcates, as was discovered by Frithjoff Nansen, ${ }^{1}$ the explorer. The headward brauch of division ascends in the case of many fibres to the grey "nuclei" of the dorsal columns in the bulb; the aboral branch descends only a short distance, one or at most a few spinal segments. Each of these branches gives off collaterals into the grey matter, especially into the grey matter of the same segmental level as the root-ganglion, whence the root-fibre in question is itself derived. The intra-spinal extent of the afferent root-cell is therefore far more expanded than is that of the efferent root-cell. The dendrites of the latter seem to be practically confined to the segment in which the cell-body lies; the processes of the afferent fibres on the hand are traceable far into segments widely distant from that into which they plunge first on entering the cord. There is, therefore, a very extensive intra-spinal overlap in the central distribution of the afferent fibres derived from each afferent root-ganglion. Whether this applies equally to the afferent root-cells connected with the viscera as to other afferent root-cells is a question. The focal and circumscript character of the areas of tenderness and referred pain studied by Head in cases of visceral disorder, and their correspondence in situation with the skin areas of distribution of the individual spinal roots suggests that the central end-distribution of these visceral afferent fibres is less diffuse and less extensive intra-spinally and more concentrated within a single segment. On the limitations of intra-spinal rootoverlap the study of the reference of visceral irritations may give most valuable light. Regarding the existence of segmental boundaries to the intra-spinal spread of

1 Bergen's Museum, 1887. 
impulses, observations such as the following illustrate the slightness of the evidence in support. If the central end of the afferent root of a thoracic nerve be carefully stimulated with gradually increasing strengths of stimulus, the musculature of the chest wall belonging to its own motor root is the first to reply, and all parts of it do not reply with equal readiness; certain portions are thrown into contraction more readily than others. The intercostales are rather late; as the intensity of the stimulus is increased, the effect, curiously enongh, is not easily pushed across the median line; long before that passes, some of the musculature supplied by the next adjacent motor roots behind and in front comes into play. It is difficult to note a distinct step in the spread, and the spread passes often a little earlier to the segment behind than to that in front. ${ }^{1}$ Yet the intra-spinal resistance-to borrow electrical terminology-is for its own afferent path in the segment stimulated a little lower than in the adjoining. There is, therefore, some functional segmentation. But in the case of the limb muscles I could not obtain such evidence. Taking the flexion-adduction of the hallux of the monkey, this reflex could be obtained from each single one of a row of the rootlets of the three last roots of the limb-plexus. When obtained from an afferent rootlet of the first sacral root it was obtained with equal facility, whichever of the motor roots supplying the short muscles of the hallux remained unserered. There was thus no evidence of a segmental barrier of resistance between the spinal segments concerned with the innervation of this muscle. These segments in regard to this muscle seem to have become so welded together as to form a physiological unit.

There is, therefore, some evidence of functional segmentation in the cord; but such evidence is yielded best by the Invertebrata. In the Vertebrata it is an ancestral heritage now so modified as to lie largely obscured from recognition. It is partly on the assumption of a functional segmentation of the spinal cord that the custo-

1 Sherrington, ‘ Phil. Trans. Roy. Soc.,’ London, 1896. 
mary manner of dealing with the spinal functions as a separate and integral chapter of physiology is justitiable. Otherwise the contents of that chapter would more properly be distributed under the various special chapters devoted to the separate senses and their organs and reactions. With Vertebrata this would, as a fact, for most purposes be the preferable plan.

The individual is a mass of living units, their activity co-ordinated together by conductive strands (nerve-cells) reacting to the environment. The environment acts on this co-ordinating system through "sense organs." Of these there are sets each attuned to certain species of environmental changes. For some changes in the environment no sense-organs have been evolved, e.g. for " Röntgen rays." The channels of access for the environment are olfactory, visual, auditory, gustatory, cutaneous, and, finally, the muscular and visceral. We might imagine the form of the individual and the disposition of the sense-organs as primitively very simple; for instance, a spheroid with a digestive cavity and sense-organs diffused over the surfaces especially the external. Such a form we should expect by evolution to become modified. Its contractile (muscular) mechanisms would obtain mechanical advantage (leverage) by elongation in certain directions. The lengthwise extension of the vertebrate body and of its lateral motor appendages, the limbs, are in so far such as might be argued $a$ priori. Such extensions involve simultaneous extension of the covering surfaces; these surfaces are sentient, and the opportunity of these as sense-organs is almost in direct ratio as their mobility. The "touch-field" is thus enlarged, and becomes enhanced with greater "depth." Perceptions of space are favoured. The tactual sensations reinforce and check more efficiently those based on the eyes, and on the semicircular canals. The visual sense owes its preponderance in providing perception of space doubtless to its stimuli emanating from environmental sources relatively remote. Its reactions thus come to usually pre- 
cede in time the other reactions occurring between the organism and the environmental object. The brightness, or the darkness, or the colour affect the organism from a greater distance, and therefore, if the organism and object be relatively rnoving, in many cases earlier than do the other qualities of the object. Sensations of the eye in this way herald and forerun sensations that will in due time come to pass through other sense organs. Hence doubtless the almost constant relation between direction of vision and direction of locomotion; the two coincide. Progression habitually takes the organism into that quarter of space already partly explored by his sense; it carries him into his visual field. In the majority of cases the visual organs are so set that their field of view is occluded as little as possible by the extension of the organism itself. They are so set as to look "out" from some projecting portion of the contour of the animal. When the form of the animal is elongate, as it so often is, mechanical advantage of leverage having been thus acquired, the visual organs approximate to one of the poles. That pole will then "lead" in locomotion-the eyes look "forward." In other words, the motor mechanism that as it develops elongates, elongates primarily "backwards." And it is covered with skin possessing the usual cutaneous sense organs. And it has its own "muscular sense" due to organs embedded in itself. Side appendages (limbs) thrown off laterally from the elongate trunk repeat the primary or axial elongation as regards mechanical leverage for motor elements and the concomitance of increased sense apparatus of muscle and of increased sensorial skin surface. But, as a rule, the viscera do not extend into the lateral appendages, although for some distance into the primary axial or vertebrate, thus ensuring increased absorbent surface. Hence there comes to be a great motor apparatus extending back behind the visual organ and containing besides muscle a certain amount of visceral cavity ; and covered with skin containing cutaneous sense-organs. This apparatus it is which chiefly voL. LXXXII. 
executes the movements of the organism as a whole. It can alter the space relations of the mouth and sense organs in regard to the environment and thus facilitate the nutrition of the organism by securing food; it can remove the individual from situations of danger or of injury. It is at the command not only of the sense organs resident in itself and in its own covering, but also of the great sense organs near that pole of the animal which its function is to drive "forward" into visual space. The pole where the great projicient senses of sight, smell, taste, hearing, and stereotropism (semicircular canals) have their organs is the pole that, by the action of the motor train attached, "leads" in progression, and the motor organ itself is after all in the main their instrument. As the animal scale is ascended it becomes their instrument more and more. The pole at which they lie is called by anatomists "the head," and the characters which the great sense organs and apparatus for intake of food impress upon it make its identification easy throughout a vast range of animal form. It is significant in the evolution of animal form that the organ that exhibits most uninterrupted and harmonious increase in development as studied successively in passing from lowest to highest is the brain. And it. is significant that in the nerrous system-segmental system as it is - the brain is developed not in those segments whose sense organs are ordinary cutaneous (tactual, \&c.), muscular and visceral, but in the segments connected with the visual, olfactory, and otic sense organs ; in other words, the brain is developed in the "head." The head is, so to say, the individual ; it has the mouth, it takes the food, including air and water, and it has the main sense organs providing the data for both space and time. To this the body, an elongated motor organ with a share of the viscera and the skin, is appended primarily as a machine for locomotion. This latter must of necessity lie at behest of the great sense organs of the head.

Hence there are nervous conductors from the great sense-organs of the head to the great motor organ which 
the contractile masses of the body together form. The spinal cord contains this strand of conductors, and it is in this sense a mere appendage of the brain. But the motor organ itself is a complex structure, built up of many parts. These, if the movements asked for by the projecting senses are to be adequately executed, must be co-ordinate in action. One of the main functions of the spinal cord as an independent organ, and apart entirely from the influence of the cranial sense organs, is the regulation of the activities of the several muscles, so that they act coordinately. This is well illustrated by analysis of the muscular movements which ensue in the limbs as result of reflex excitation in the purely spinal animal. In the limb region, in response to an excitation of a single afferent root, the spinal discharge of centrifugal impulses evoked tends to occur by more than one efferent root. ${ }^{1}$ It is a plurisegmental discharge to plurisegmental muscles. But though plurisegmental it is in each segment only fractional. It treats any one muscle of the limb as an entity, either exciting it wholly or leaving it wholly alone. The contraction of the various segmental portions of the plurisegmental muscle are thus co-ordinated together. They are knit together by a co-ordination which is wholly spinal. Further, the co-ordination of antagonistic muscles is managed by the spinal cord. After Winslow ${ }^{2}$ and Duchenne ${ }^{3}$ it became current doctrine that antagonistic muscles act co-operatively in the sense that the antagonist by contracting synchronously with the prime muscle modulates and helps to guide and control the nicety of the movement. I have shown that in spinal and in bulbospinal reactions ${ }^{4}$ (Pl. XVI, fig. 1), and also in many cortical $^{5}$ (Pl. XVI, fig. 2), the reverse is in reality the condition of the antagonist. It is, in fact, relaxed, by inhibi-

1 Sherrington, 'Journ. of Physiol.,' xiii, 1892.

2 'Anatomical Expositions,' \&c., 1749.

3 'Localisation,' \&c., 1867, and Rieger, 'Archiv f. Psych.,' xiii.

+ 'Journ. of Physiol.,' vol. xiii, 1892.

5 'Proc. Roy. Soc.,' vol. lii, 1893. See also Hering and Sherrington, 'Pfüger's Archiv', 1897. 
tion of its tonus and of any pre-existent contraction, at the same moment as the opposed muscle is by pressor influence thrown into contraction. For instance, when the motor neurons of the flexor muscles of the elbow are excited by pressor influences in a spinal reflex, the motor neurons for the extensor muscles are simultaneously inhibited as a part of the same spinal reflex (Pl. XVI, fig. 3). But not only are certain movements about a single joint opposed one to the other, certain movements at one joint are opposed to certain movements at neighbouring joints. Thus the extensors of the knee may be called antergetic not only to the flexors of the knee, but also to the flexors of the hip (Pl. XVII, fig. 1). In such cases the " reciprocal innervation," as I have ventured to style this mode of co-ordination, still holds good. The groups of motor neurons selected by the reflex action as it irradiates over spinal segments lying apart in the limb series are still those of synergetic muscles. For instance, while the reflex movement evoked by excitation of the fourth lumbar root or that responsive to the long saphenous nerve usually primarily contracts the flexors of the hip, it involves next not the antergetic muscles in the nearest spinal segments (e.g. vasti and crureus), but inhibits these and embouches into the synergetic of more distant segments, e. g. the hamstring muscles. In this way the reflex action, by its "spread," develops a combined movement-synthesises a harmony. ${ }^{1}$ The mere inspection of a movement without further analysis of it is a very insecure guide toward judgment whether it be coordinate. The joints and muscles of the limb have been evolved contemporaneously and together in the course of the history of the individual and of the species. No muscle can therefore be thrown into action which will move the limb in any which is an unnatural direction. But from the above given criteria co-ordination is abundantly shown to result from the independent power of the spinal arcs, altogether apart from the influence of the 1 'Philos. Trans. Roy. Soc.,' 1896. 
great cranial sense organs and of the cerebral arcs superposed upon them. These senses and the brain find elementary co-ordination of the skeletal musculature an achievement already provided and to hand in the spinal cord itself. No doubt the product of the instrument is, with the instrument itself, given over to their use in the reactions they elicit from the spinal musculature.

Now a co-ordinate movement must be "purposive" in character. Considered in the light of the Darwinian theory, the normal connections between any afferent path (e. $g$. piece of skin) and the motor apparatus conjoined with it, can only be such as to lead to "purposive" movement. The question rises, what are the purposes of which the reflex movements of a spinal animal are indicative.

It is curious that the sense organs of both skin and muscle seem to evoke reflexly very much the same movements the one as the other. Irritation of the skin of the foot evokes flexion at knee and hip ; so also does stretching the muscular sense apparatus in the muscles and ligaments at the pedal and ankle-joints. Certain reflexes are, however, peculiar to skin stimuli; such are the "scratch" reflex and the "shake" reflex in the spinal dog. The former is started by stimuli applied to the skin of the trunk, perhaps especially of side, flank, and shoulder. It consists in a rhythmic flexion of the hind limb, causing it to execute scratching movement. The latter is started from the skin of the trunk, especially perhaps along the middorsal line, and consists in a shake of the whole body, like that given by a dog on coming wet from water. I have seen it occur synchronously in the neck and head above the lesion, and in the "spinal" part of the animal. Spinal transection had been performed at the sixth cervical level; on scratching the skin over the scapula-partly anæsthetic, partly still sensitivea "shake" was induced in the musculature above as well as behind the lesion. Grainger ${ }^{1}$ concluded years 
ago (1837) that spinal cutaneous reflex movements "are either of a preservative character or resembling the motions which the function of the organ requires." From the tegument of the spinal creature reflex movements of "preening" or "cleansing" can be elicited. The "preening" actions of the spinal insect and crustacean fall into this category. The spinal frog wipes irritants from its skin. The posturing of the hind limbs and tail of the spinal dog concurrently with reflex evacuation of the fæces, keeping the body from being soiled, come into the same class of purpose as the "shaking" and "scratching" reflexes above mentioned. The conjunctival reflex closure of the eye, essentially a cutaneous, and, from the broad point of view, a spinal reflex, is similarly preservative of the sensorial surface whence it is initiated.

Another purpose which seems unmistakably signified by spinal reflex movements is progression. To apply the appropriate stimulus for this is perhaps a little difficult. Dytiscus, the water-beetle, when reduced to a spinal condition does not run when placed on a firm surface, although each of its legs responds by free movement when individually stimulated. But on being placed in water it immediately swims ${ }^{1}$ co-ordinately forwards. I find the spinal frog when placed in water at $38^{\circ} \mathrm{C}$. swims for a short time co-ordinately forward with good bilateral strokes. Water at that temperature acts as a stimulus to the skin of the frog. The fish and triton after removal of the brain exhibit co-ordinate progression. In the dog, after spinal transection at the seventh cervical level, skin stimuli to the under surface of the body cause co-ordinate movements of all four limbs, the posture assumed taking the diagonal symmetry indicative of quadrupedal progression. ${ }^{2}$ Even when the spinal transection is in the lumbar region, pressure upon the pad usually elicits protraction and flexion of hip and knee in the homonymous hind limb,

1 Carpenter, 'Comparative Physiology,' London, 1850.

2 Sherrington, 'Journ. of Physiol.,' xx, 1897. 
and retraction with extension of hip and knee in the crossed hind limb. The spinal reflexes significant of progression seem to contribute chiefly toward preparatory posture in readiness for onset of action executed by the musculature under the driving of higher centres. Thus the well-known reflex spinal posture of the frog is flexion of the hind limbs, the extensors of the joints being taut and ready for the jump. Again with the primary reflex from the pedal end of the limb of the mammal. This does not, as might have been expected, take the form of the propelling stroke, the extensor push, that thrusts the body forward. On the contrary, it lifts the limb from the ground. This is, no doubt, the phase of the limb's movement of progression which requires the least output of force; it resembles in so far the expiratory phase preparatory for the inspiratory of respiratory movement; it may almost be likened to the diastole of the heart, and, like both these, it is preparatory for a succeeding phase of greater muscular effort. That phase ensues also in the spinal animal, but it is the less easy to obtain and less soon emerges from the depression of traumatic shock.

The spinal reflexes which in their results approximate most closely to the normal reactions of the unmutilated individual, are those connected with the pelvic and abdominal viscera. Defæcation, micturition, parturition, menstruation, genital turgor, seminal emission-these and other analogons functions are executed as spinal reflexes in a manner presenting little or no physiological defect from the normal. Their "purpose" is clear. If the bulb be included with the spinal cord, and these together, including their peripheral nerves, be isolated from the rest of the nervous system, the animal as regards its visceral life, including that of the heart and lungs, is practically intact. The viscus concerned with the intaking of gaseous food is innervated from a cranial nerve, the vagus; hence its "nervous centres" lie in the bulb. An important part of the circulatory muscles, namely the cardiac, is similarly innervated by a cranial nerve, 
hence likewise has a bulbar nerrous centre. The existence of respiratory centres for the muscles of inspiration and expiration as independent from the bulbar centre remains still unproven. The existence of spinal vaso-motor centres subsidiary to the bulbar is asserted on the ground that it is still possible to obtain reflex alterations of blood pressure when the cord has been transected at calamus scriptorius if strychnia be exhibited to heighten its reflex activity. To demonstrate the existence of potent vaso-motor centres in the spinal cord does not, however, require the exhibition of strychnia. It is enough to allow the lapse of a few days or, better, weeks after transection of the cord in the cervical region. The blood pressure will then be found to have in the carotid of the dog a mean value of something over $100 \mathrm{~mm}$. of mercury (Pl. XVII, fig. 2). By stimulating the skin mechanically or by temperature changes, or by faradising the central end of an afferent nerve, e. g. of the foot, reflex increase of blood pressure raising it 20 to $30 \mathrm{~mm}$. of $\mathrm{Hg}$ is easily obtained. It is only in the first few hours immediately succeeding the initial trauma of transection that the cord being in a condition of shock gives no reflex response by its vascular musculature any more than by its skeletal musculature. This visceral shock seems no more severe in the higher than in the lower vertebrata. It is as regards the performances of the skeletal musculature that great difference exists in regard to shock distinguishing between the spinal frog and spinal monkey. I have ventured to suggest that the spinal shock of the latter animal is connected with an isolation dystrophy such as occurs in cases where nerve-cells habitually actuated by other nerve-cells are suddenly and completely cut off from their influence. That the difference is very great and real between lower and higher types in this respect of spinal shock is shown by such instances as the following. The cat from which the Rolandic area of the cortex has been removed, so as to ablate the whole of the limb centres from one hemisphere, if some weeks later "decerebrate rigidity" be induced in its limbs, yields the 
rigidity without perceptible difference between the sides both right and left. But in the monkey similarly prepared, a great difference between the limbs of the two sides is apparent. The rigidity on the side crossed to the cerebral lesion is very much less than on the homonymous side. At the same time it must not be thought that the whole depression of function in the parts innervated behind the spinal transection is due to removal from them of merely cerebral influence. That that cannot be the case is shown by a fact that I have several times had opportunity to observe, namely, that the performance of a second spinal transection some weeks later, and some segments behind a former spinal transection, is followed by the recrudescence of many of the original symptoms of depression of function that had followed the original transection. It is significant that such a second transection behind a previous one causes a considerable increase in the descending spinal degeneration, showing that there descend from upper parts of the spinal cord many channels arising in those upper spinal regions and connecting them with other spinal regions further back.

Whence comes the great difference existent between, on the one hand, ape and man, and, on the other, fish and frog, as regards the depression of the reactions of the skeletal musculature ensuent upon total transverse lesion of the spinal cord?

To refer briefly for a moment to initial shock due to spinal section in the monkey, there can hardly be witnessed a more striking phenomenon in the whole physiology of the nervous system. From the limp limbs, even if the knee-jerks be elicitable, no responsive movement, beyond perhaps a feeble tremulous adduction or bending of the thumb or hallux, can be evoked even by insults of a character severe in the extreme. That which the delicate yellow spot is to the sensifacient sheet of the retina, may the thumb and index be said to constitute in the great sensifacient field of the limb. Nevertheless a hot iron 
laid right across the thumb, index, and palm remains an absolutely impotent excitant, or able only to evoke a faint flexion of the thumb; the crushing of a finger has no greater effect. A huge afferent nerve, such as the internal saphenous, containing some five thousand sensory nervefibres, when laid across the electrodes and subjected to currents absolutely unbearable upon the tongue, elicits no response, and probably no movement whatsoever. To the whole popliteal nerve, representing an area of sentient skin which includes the entire sole and much of the leg besides, intolerable faradisation can be applied without response. A more impassable condition of block or torpor can hardly be imagined; its depth of negation resembles, to superficial examination, profound chloroform poisoning.

Shock is not only more severe in the monkey than in the other laboratory types, but it is also more lasting, and its symptoms are more profound and prolonged than in any other animal I have observed. The symptoms of shock, in many monkeys, persist for days instead of hours and minutes, as in cat and dog. It is important to note that in the monkey, nuch of what we are, from observations upon the lower animal types, inclined to regard as temporary, and relegate to block or "shock," in Goltz's language "Hemmungserscheinungen" - not "Ausfallserscheinungen"-proves, under prolonged observation to be, I must admit, permanent; in fact, to be true deficiency phenomenon. Every histologist acquainted with the comparative structure of the spinal cord in the ape and in the dog must have been impressed with the far greater complexity obvious in the former. The above evidence is in accord with that, for it shows that the same trauma inflicted upon the cord leads, in the monkey, to much heavier permanent defect than in the dog; just as, in fact, ablations of the cortex cerebri are pregnant with far greater "Ausfallserscheinungen" in the monkey (Ferrier, H. Munk, Schäfer, Mott) than in the dog (Goltz). It is reasonable to argue still severer results in the case of the human spinal cord; 
of which, again, we know the minute structure to be yet more complex still. The permanent damage done is therefore, as well as the initial shock, disproportionately greater in monkey than in cat and dog.

My own experience leads me to think that the condition of a spinal cord isolated by a spinal transection is often more normal a few hours after the transection than it is when long periods of weeks and months are allowed to elapse. I am well aware that this is contrary to the opinion of Goltz and others. 'The advantage believed to accrue from waiting is that the phenomena of shock may have time to pass off as completely as possible. How long the phenomena of shock may last at longest is a question on which very different views are held. Goltz, to whose trenchant observations and bold system of experiment we owe so much of our knowledge of the physiology of the central nervous system, is the founder of a school which works in the belief that the phenomenon of shock may persist for months, even years. It is, as far as not, merely a matter of nomenclature, a question on which no definite decision seems as yet possible. I myself have gradually been driven to the belief that "shock" does not take long to pass off, $i . e$. does not at longest persist for more than a few weeks. I am not considering here the complications arising out of long badly-healing and suppurative wounds, and the continual irritation they may produce if situate in the nervous system. But though shock passes off, the alterations produced in the isolated cord or piece of cord (by permanent withdrawal of the influences it has lived accustomed to receive from other portions of the central nervous system) progress, and are in a sense cumulative. The decreasing depression merges-at present inextricably for us-in the increasing onset of an "isolation-dystrophy." Much of what is called "shock," in regard to the mammalian cord, is, I believe, due to "isolation-dystrophy," and is really permanent,-that is to say, would not pass away if the animal were to live 
healthily for any number of years. The most favourable time for the examination of the independent capabilities of the spinal cord is that when the sum of "shock" and "isolation-dystrophy" together is of smallest amount. That time, compounded as it is of two such variable factors, is itself extraordinarily variable. In result of spinal transectiou in monkey, I am sure that "shock" lasts longer, and that "isolation-dystrophy" comes on earlier than in the other animal types commonly observed in the laboratory. It is the conjunction of the periods of these two phenomena which renders so difficult and so largely defeats attempts at observations on proper spinal reactions of the monkey. If the overlap of the two is great, then no spinal reflexes, or only the merest traces of them, may be observable. In man it is only natural to suppose-and what clinical experience I have had access to strengthens me in the belief-that even more than in monkey will "shock" be protracted, and "isolation-dystrophy" speedy and severe. The observations of Bastian, ${ }^{1}$ Bowlby, ${ }^{2}$ and Bruns, ${ }^{3}$ teach us that the clinical picture of the effects of total transverse lesions of the human spinal cord does not accord in the way that. medical text-books have been wont to describe with the long known results obtained from the transected cord by the physiologist. Older physiological experiments are, however, not based on nervous systems so approximate. to the human as is that of Macacus, Cercocebus, \&c. Of these latter I would say that their condition after spinal transection commonly resembles in its features in the most striking manner the condition of spinal depression observed after spinal translesion in man, and considered by Bastian to be the typical status.

My results on monkeys bear out strikingly and fully what Bastian describes as the typical condition in man, after complete transverse destruction across the cord.

1 'Medico-Chirurgical Transactions,' London, 1891.

2 Ibid.

3 'Neurologisches Centralblatt,' Berlin, 1893. 
The chief difference is that in the monkey in most cases - partly, perhaps, because the lesion is more localised by experimental infliction than by accidental-the depression is not so severe. For instance, the knee-jerk, which disappears almost immediately after the transection, returns usually in a week or ten days, ${ }^{1}$-often, however, not for three weeks; occasionally, on the other hand, in ten minutes.

The great motor organ-the skeletal musculature-is at the command of the sense-organs. Not only is it actuated by contact sensations evoked in the neural system of the individual by the tangible quality of the circumambient environment; each light that causes the animal to move, each sound, each odour, shows how the motor machine lies at the behest of the great sense-organs of the head. Now these latter are broadly distinguishable from the sense-organs of the trunk inasmuch as they subserve sense possessing the quale of "projection." For each individual creature the material universe is thus separated into two parts, the part that is "me," and the part that is " not me." I think it was Lotze who said that doubtless to the trodden worm, of these two halves the trodden "me" shall surely appear the greater. By a high spinal transection the splendid motor machinery of the vertebrate is practically as a whole and at one stroke severed from all the universe except that fraction the " material me." The deeper depression of reaction into which the higher animal as contrasted with the lower sinks when made "spinal," appears to me significant of this, that in the higher types, more than in the lower, the great projecting senses actuate the motor organ, and impel the motions of the individual. That deeper depression shows how, as the individual ascends the scale of being, the more percipient, the more cognizant does it become of the circumambient universe outside that is "not me;" and thus the latter acquires a more and more preponderant directive influence over those reflections, those expressions of the creature's neural states, its "doings."

\footnotetext{
1 'Foster's Juurnal of Physiology,' vol. xiii, 1892.
} 


\title{
DESCRIPTION OF PLATES XIII-XVII
}

\author{
Illustrating The Spinal Animal (Charles S. Sherrington, \\ M.A., M.D., F.R.S.).
}

\section{Plate XIII}

FIG. 1.-This figure indicates the position of the limits of the skin-fields of the cervical and brachial spinal nerve-roots. Both the anterior and the posterior borders of the fields are indicated in the diagram, which renders the figure somewhat confusing. A portion of the limit of each field is, however, omitted, namely, that portion of it which joins the portions of the adjacent fields to form the ventral axial line of the limb. This combined portion of the borders forming the ventral axial line of the limb is represented by itself in fig. 2 of this same Plate XIII. The lines which in fig. 1 indicate the posterior limits of the fields are finely dotted lines, thus .............. ; the lines which indicate the anterior limits of the fields are simply broken, thus -- --. The number attached to each line signifies the number of the cervical or thoracic nerve-root in the enumeration of the vertebral series; thus 4--signifies the position of the anterior limit of the skin-field belonging to the fourth cervical nerve-root, and $1 \ldots$ signifies the position of the posterior limit of the skin-field belonging to the first thoracic nerve-root. The line $v$ signifies the posterior border of skin-field of the cranial fifth nerve.

FrG. 2 shows the position of the ventral axial line of the brachial limb, v. A. L., as formed by the conjunction along the place indicated of the borders of the consecutive skin-fields of the brachial nerve-roots.

FrGs. 3 AND 4.-These figures indicate in the same way as the preceding the positions of the limits of the skin-fields of the cervical and brachial nerve-roots, and how from those limits an axial line of the limb is revealed by their conjunction along a certain line. These figures differ from the two preceding only in giving the dorsal aspect of the limb instead of the ventral, D. A. L., the dorsal axial line. In fig. 3 the line $\mathrm{V}$ signifies the posterior limit of the fifth cranial nerve.

\section{Plate XIV}

B. $\mathbf{P}$. = the curotid blood-pressure in a cat (chloroform and ether, in addition to morphia and curare). An injection of $2 \frac{1}{2}$ cubic centimetres of normal saline solution at body temperature was made into the common bile-duct at the place marked by the signal. A marked rise of the carotid pressure ensued. The time is marked in seconds. 


\section{Plate XV}

B. P. = blood-pressure tracing from the carotid artery of the cat. s. Electric signal. T. Time marked in seconds. From 1 to 0 on the signal trace 1 cubic ceutimetre of normal saline solution at body temperature was introduced from a reservoir into the left ureter, about five seconds. The animal was chemically narcotised with a mixture of chloroform and ether, and by a hypodermic injection of morphia: it was paralysed with curare. Tracing reads from left to right.

\section{Plate XVI}

FIG. 1.-Reciprocal innervation at the elbows of the monkey, both reacting under one spinal reflex. Flexion of one elbow is seen to accompany extension at the other, and at both reciprocal innervation of the antagonistic muscles is evident.

Fia. 2.-Reciprocal innervation of the lateral muscles of the eyeballs under cortical excitation of the left hemisphere, producing consensual movement of the eyeballs to the right, the sixth nerve of the right side having been severed at its exit from the base of the brain. The right eyeball is shown to move to the right up to the median position; the left to beyond that.

Fra. 3.-Reciprocal innervation instanced by the extensors and flexors of the elbow-joint in the monkey, obtained as a reflex from the twig of the radial nerve, the animal being in the condition of "decerebrate rigidity." The tonic contraction of the extensors relaxes as the reflex contraction of the flexors sets in.

\section{Pente XViI}

FrG. 1.-Similar to the above, but obtained from the flexors and extensors of the knee-joint, and with levers, writing not in harmonious sense as above but in opposing sense, so that the relaxation of the lower rectus femoris muscle is written upwards.

FIG. 2.-B. P. Graphic record of the arterial blood-pressure of a dog (carotid artery) under chloroform and ether after morphia, and in addition to curare. The spinal cord had been completely severed transversely at the seventh cervical segment eight weeks prior to the observation. The gap in the signul trace shows when, for five seconds, the toes of one hind foot were forcibly extended. The movement caused a reflex rise in the arterial blood-pressure, followed by a temporary fall. Zero of B.P. marked the level of the float in the manometer under atmospheric pressure. It is noteworthy that there is acceleration of pulse as well as rise of the arterial pressure. 
Plate XIII. .

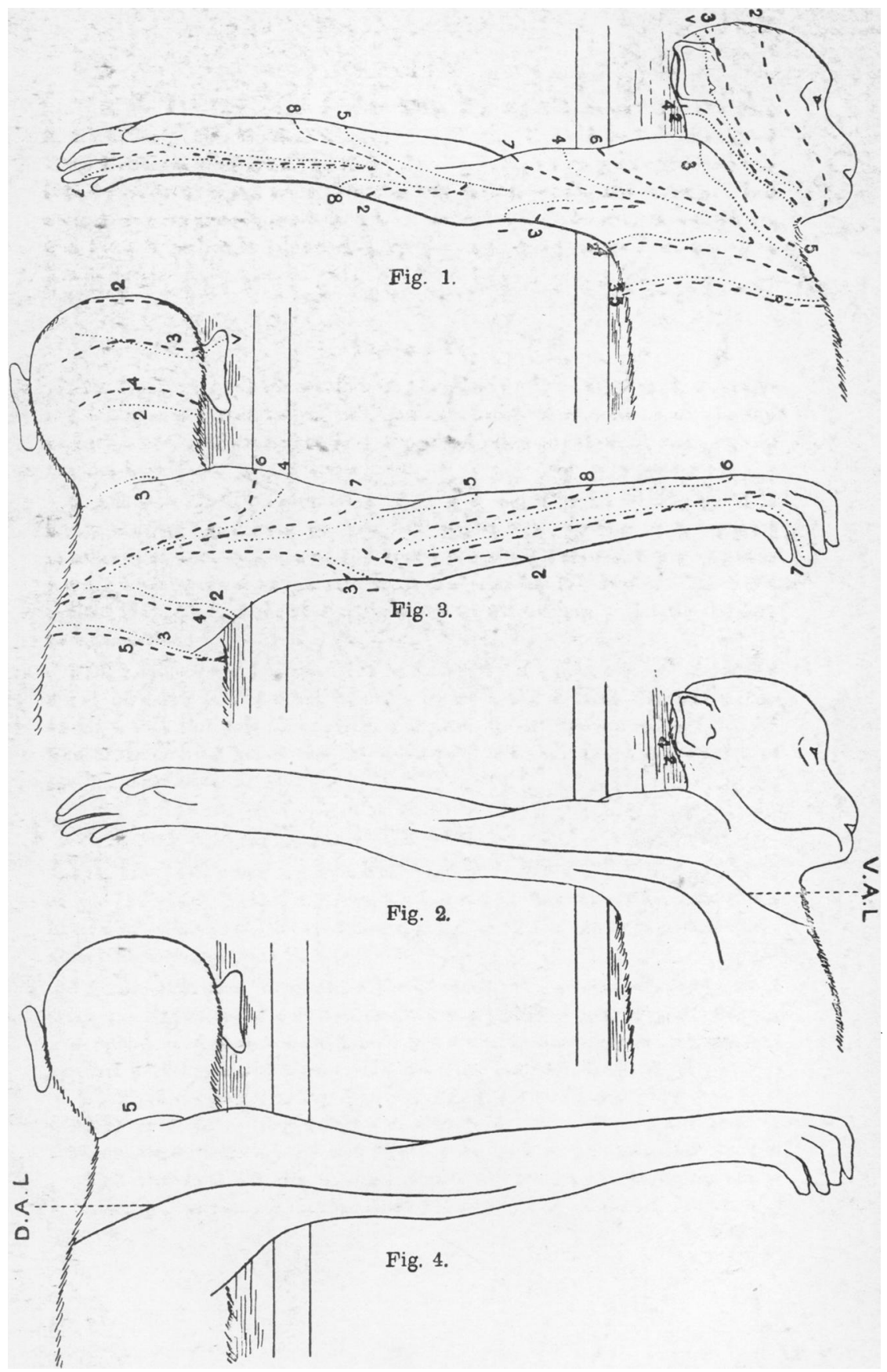

Med. Chir. Trans., Vol. LXXXII. 
Plate XIV.

Med.-Chir. Trans., Vol. LXXXII.

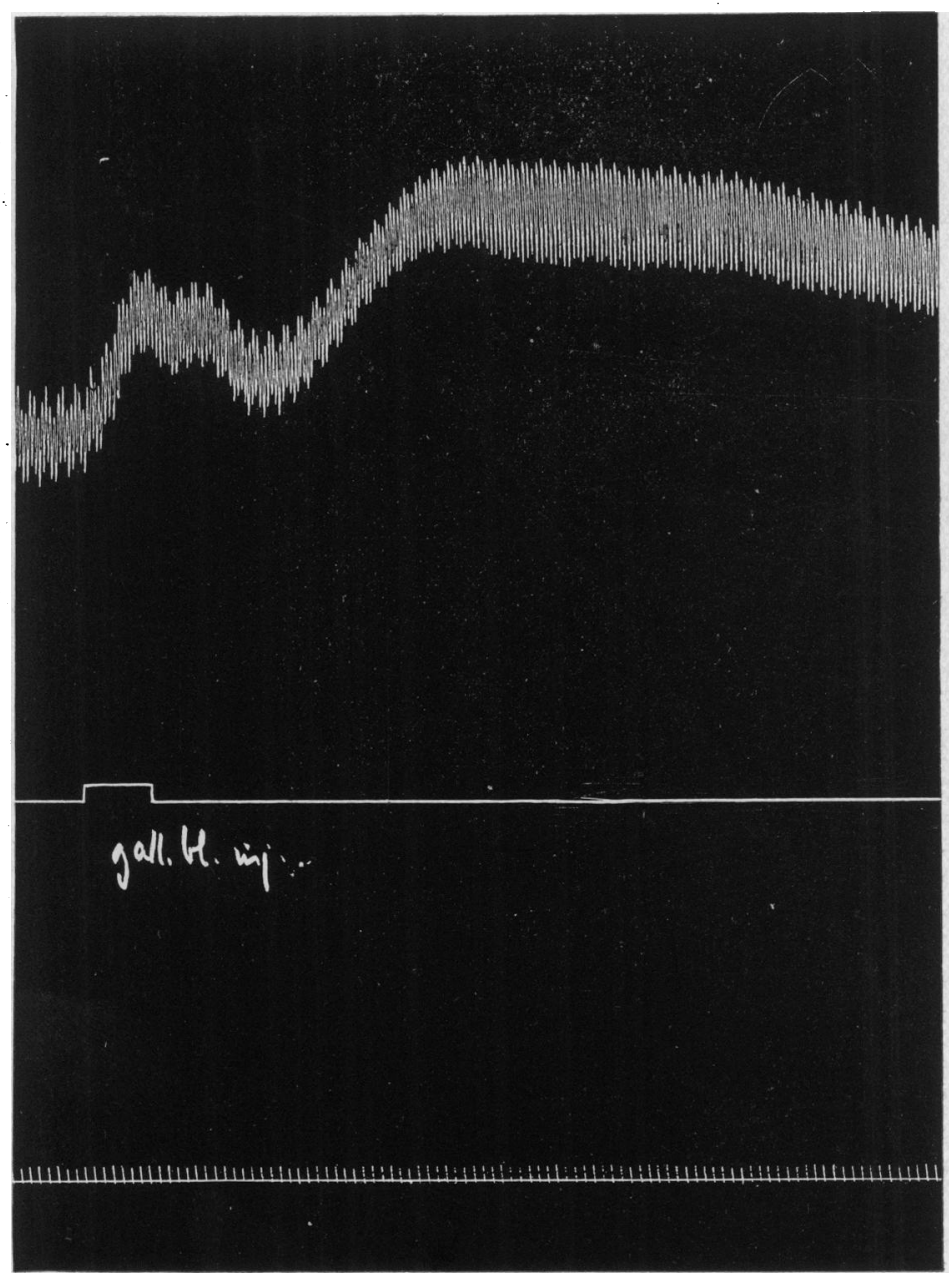

B. $\mathrm{P}$.

Signal.

Time. 


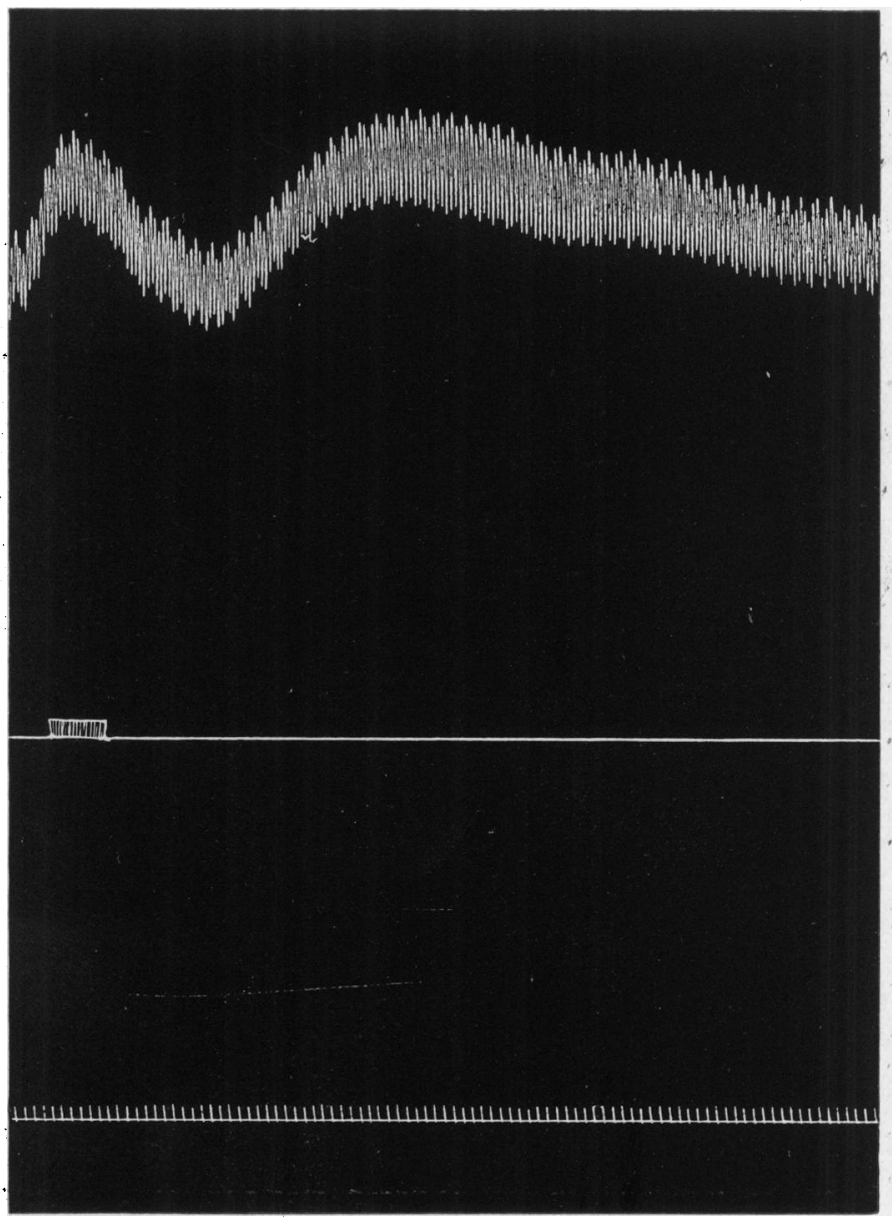

B. P. 
Plate XVI.

Med.-Chir. Trans., Vol, LXXXII.

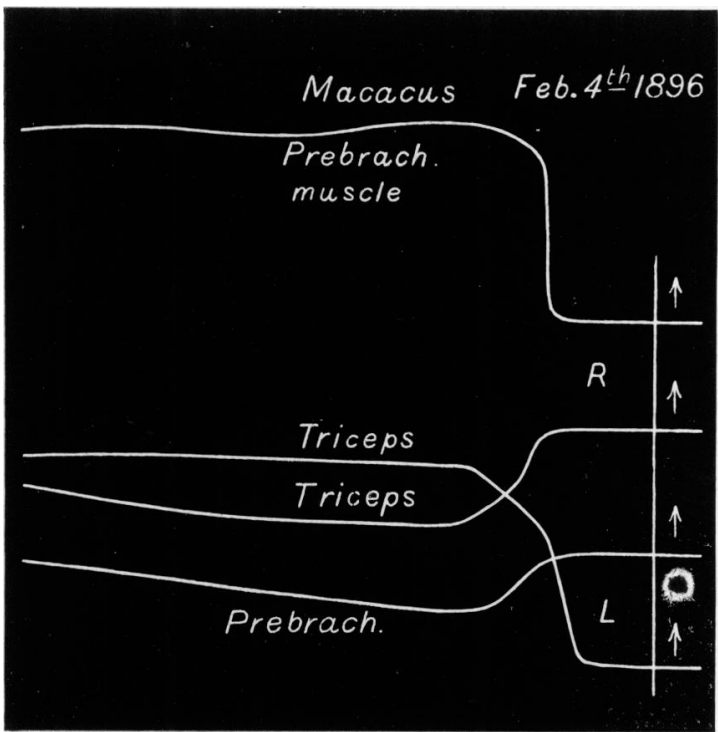

F[a, 1.

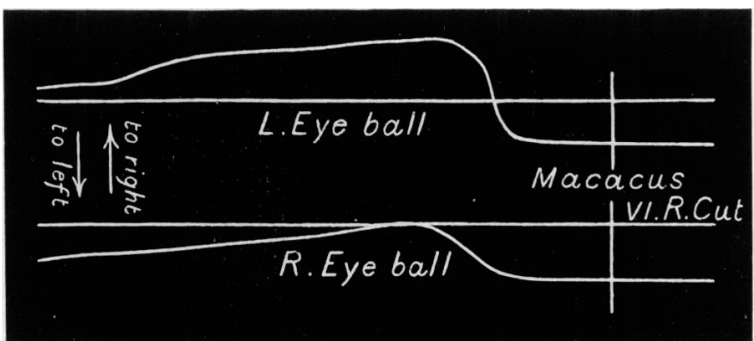

FIG. 2.

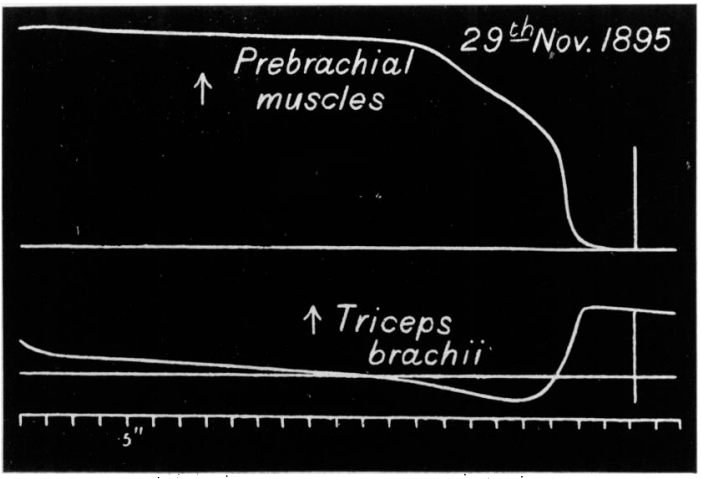

FIG. 3. 
Plate XVII.

Med.-Chir. Trans., Vol. LXXXII.

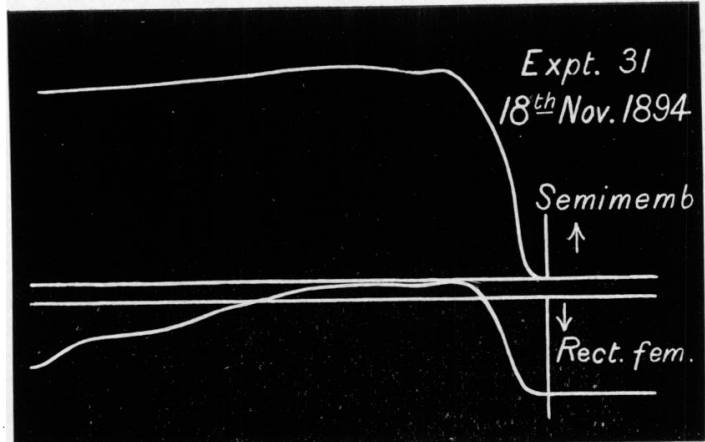

Fia. 1.

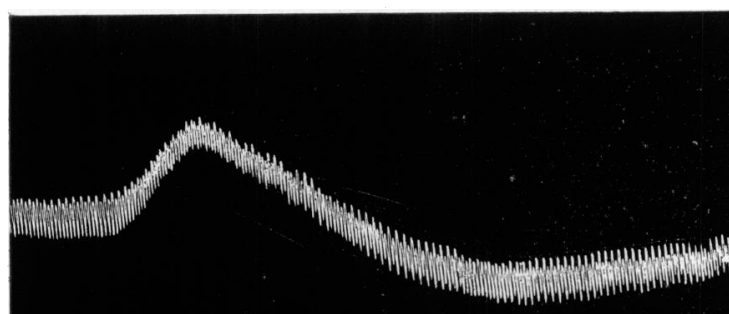

B. P.

Zero of B. P.

\section{lending hivd fort .}

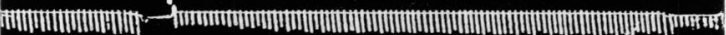

Signal.

Time. 